\title{
Vaccines Targeting PSCK9 for the Treatment of Hyperlipidemia
}

\author{
Stefan Toth $\cdot$ Dominik Pella $\cdot$ Jan Fedacko
}

Received: June 5, 2020 / Published online: July 31, 2020

(C) The Author(s) 2020

\section{ABSTRACT}

Despite progress in both primary and secondary prevention, cardiovascular diseases (CVD) are still the largest group of ailments contributing to morbidity and mortality worldwide. Atherosclerotic changes, the primary pathological substrate for CVD, are closely related to hypercholesterolemia. Therefore, the treatment of hypercholesterolemia is a key therapeutic strategy for CVD management. Statins, as the gold standard in the treatment of hypercholesterolemia, have shown enhanced cardiac

Digital features To view digital features for this article go to https://doi.org/10.6084/m9.figshare.12600008.

S. Toth

SLOVACRIN, Slovak Clinical Research Infrastructure Network, Pavol Jozef Safarik University, Trieda SNP 1, 04011 Kosice, Slovakia

D. Pella

1st Department of Cardiology, East Slovak Institute of Cardiovascular Diseases, Faculty of Medicine, Pavol Jozef Safarik University, Ondavská 8, 04011 Košice, Slovakia

J. Fedacko $(\bowtie)$

MEDIPARK, University Research Park for Preclinical and Clinical Research, Pavol Jozef Safarik University, Trieda SNP 1, 04011 Kosice, Slovakia

e-mail: janfedacko@hotmail.com;

jan.fedacko@upjs.sk outcomes in many randomized clinical trials. However, often despite the maximum allowed and tolerated dosage of statins, we are not able to reach the target cholesterol levels, and thus patients persist at an increased cardiovascular risk. Recently, most of the large clinical studies in the field of preventive cardiology have focused on proprotein convertase subtilisin kexin type 9 (PCSK9) and its activity regulation. PCSK9 plays an essential role in the metabolism of LDL particles by inhibiting LDL receptor recirculation to the cell surface. Recent studies have shown that inhibition of PCSK9 by the administration of monoclonal antibodies is capable of significantly reducing LDL levels (up to an additional $60 \%$ ) as well as reducing the incidence of CVD. However, this treatment procedure of administering the anti-PCSK9 antibodies, most frequently two times a month, has its limitations in terms of time, patient adherence, and nevertheless cost. Administration of active vaccination instead of passive immunization with anti-PCSK9 antibodies may be an effective way of controlling blood cholesterol levels. However, clinical data, as well as human testing, are still inadequate. This work aims to provide an overview of PCSK9 vaccines and their potential clinical benefit.

Keywords: Antibody; Antigen; Atherosclerosis; PCSK9; Vaccine 


\section{Key Summary Points}

Methods of activation of immune system by vaccination to produce antibodies against self-antigens have been proven to be effective in several diseases such as cancer and hypertension.

Several preclinical studies have manifested successful induction of anti-PCSK9 antibodies production by special epitope/ peptide vaccines, however clinical studies with sufficient results are still missing.

\section{INTRODUCTION}

Atherosclerosis is defined as a degenerative-inflammatory disease affecting the artery wall; however, it shows characteristics of an autoimmune reaction against apolipoprotein B particles, the best-known atherogenic agent. Many processes are involved in atherogenesis. One of the most significant factors in development is plasma cholesterol concentration. Several studies have been performed proving the direct correlation between the plasma cholesterol and LDL concentrations and the prevalence of major cardiovascular events and in general directly and indirectly cardiovascular diseaseassociated morbidity and mortality [1]. Other autoimmune characteristics of atherosclerosis include CD8 and CD4 helper cells accumulation in the atheroma as the reaction to oxidized LDL, ApoB, and other autoantigens [2]. The multiple factors involved in atherogenesis highlight the multiple possibilities of atherosclerotic process management.

Therapeutic strategies to reduce levels of LDL cholesterol (LDL-C) are the gold standard in the management of patients with cardiovascular diseases [3]. According to the World Health Organization can be up to $80 \%$ of cases of coronary artery disease (CAD) to prevent their occurrence, progression, and possible complications [4]. The results of several studies suggest that lipid-lowering statin (HMG-CoA reductase inhibitor) treatment is the most effective method. In the case of sufficiently indicated LDL-C lowering drugs and with proper adherence to the therapy, the risk of MACE could be reduced by up to $40 \%$. However, statin therapy can be associated with negative pleiotropic effects such as myopathy or even rhabdomyolysis, and this can contribute on the fact that at least $20 \%$ of high-risk patients will not reach the target LDL-C levels with solo statin therapy either because of the lower dose as required or because of the statin therapy discontinuance [5].

The other key factor playing an important role could be bad adherence to statin therapy. Nowadays, most of the accessible lipid-lowering agents are administered once per day, and to reach the therapeutic approach of lowered CV risk, we need several years to manifest the desired effect. Those factors are highly participating in the adherence of the patients to statin therapy [6].

Persistent cardiovascular risk, as well as efforts to reach even lower target values of LDL and lower the CV risk, have further motivated the emergence and research of many other potential hypolipidemics.

The aim of this review article is to make an overview of PCSK9 inhibition with a focus on the possibilities of active vaccination inducing endogenous anti-PCSK9 antibodies production. This article is based on previously conducted studies and does not contain any studies with human participants or animals performed by any of the authors.

\section{PCSK9 AND ITS INHIBITION}

Proprotein convertase subtilisin/kexin type 9 (PCSK9) represents a new therapeutic target in the management of dyslipidemias. PCSK9 is a secretory protein, primarily produced by hepatocytes, but many other tissues and cell types have been proven to express the PCSK9 gene [7]. Mechanistically, after the initial secretion, PCSK9 circulates in the bloodstream and binds to the LDL-R predominantly on the surface of hepatocytes via binding to the growth factor- 
like repeat A catalytic domain, which is responsible for the recirculation of the LDL-R to the cellular surface [8-10]). One LDL-R has the ability to transport 3000-6000 LDL particles from extracellular fluid typically, however after the binding of PCSK9 to the EGF-A domain, the normal recirculation of the LDL-R is blocked, and the lysosomal degradation is enhanced.

There are several naturally occurring variances in the PCSK9 activities. The most common variants are gain- or loss-of-function PCSK9 gene mutations [11]. Several mendelian randomizations and observational studies $[12,13]$ have associated gain of function mutations with autosomal dominant hypercholesterolemia and early onset of cardiovascular diseases. However, loss-of-function mutations were connected with the decrease of LDL-C by up to $25 \%$ and a significant decrease of the cardiovascular risk of carriers without significant side effects [14].

Several preclinical and clinical studies have focused on the inhibition of the PCSK9 activity and validated safety of PCSK9 inhibition has encouraged the development of novel PCSK9 inhibitors. There were three the most notable large clinical studies with the clinical impact changing the treatment of dyslipidemia [15]. FOURIER (Further Cardiovascular Outcomes Research With PCSK9 Inhibition in Subjects With Elevated Risk) was the first completed anti-PCSK9 double-blinded multicenter trial with evolocumab, fully human antibody including 27,564 high cardiovascular risk volunteers [16]. Patients received either $140 \mathrm{mg}$ of evolocumab every 2 weeks or $420 \mathrm{mg}$ every 4 weeks or placebo. Results showed that evolocumab treatment decreased baseline LDL-C by up to $59 \%$. Relative risk reduction in comparison with the placebo group was 15\%. Risk of MI was decreased by $27 \%$, of stroke by $21 \%$. From the whole treated group, $0.3 \%$ of patients exhibited the production of binding antibodies against evolocumab, but not neutralizing.

The next study made with a fully humanized antibody was an ODYSSEY Outcomes (Evaluation of Cardiovascular Outcomes After an ACS During Treatment With Alirocumab) trial that enrolled 18,924 volunteers who had an acute coronary syndrome in last 12 months and who did not reach the levels of LDL-C $<70 \mathrm{mg} / \mathrm{dl}$ $[17,18]$. The target LDL-C levels were between 25 and $50 \mathrm{mg} / \mathrm{dl}$ but not lower than $15 \mathrm{mg} / \mathrm{dl}$. In the case of low levels, therapy was discontinued, which was the case in $8 \%$ of the volunteers. Risk reduction in the ODYSSEY Outcome trial was comparable to the FOURIER trial; $15 \%$ reduction in primary endpoints (first occurrence of CHD death, non-fatal MI, fatal/ nonfatal stroke, unstable angina pectoris requiring the admission to the hospital). Concentrations of LDL-C decreased after 4 weeks by up to $62 \%$ and was decreased by $44.7 \%$ after 4 years of the follow-up.

Despite great progress in the treatment of dyslipidemias due to PCSK9 inhibitors, as well as the low values that we managed to obtain due to the combination of statins and PCSK9, several disadvantages of this treatment persist. A good example is a short half-life of antibodies in vivo, which may reduce long-term adherence to treatment (however, still higher as in the case of statins): according to the studies, the number of patients who discontinued or break the antiPCSK9 therapeutic scheme can be up to $8.5 \%$. However, this number can be higher, because most of the studies were done during the clinical trials, which can mean that adherence can be lower in real-life data and long-term followups [19]. The high cost of treatment may especially limit the full use of the clinical benefits of these drugs. A typical regimen for PCSK9 antibodies is twice a month, which, combined with high monthly and annual costs, has limited the widespread use of this category of drugs, despite the recommendations in the guidelines.

Important competitor of passive, however also active immunization are the new treatment strategies with small interfering RNA, such as inclisiran, which has significant results in phase III clinical trials [20]. Inclisiran is a small interfering RNA decreasing the hepatic synthesis of PCSK9. Studies ORION-10 and ORION-11 have enrolled patients with atherosclerotic cardiovascular disease, respectively patients with disease risk equivalent. These studies have shown significant LDL cholesterol reduction by up to $50 \%$ with generally similar adverse effects in comparison to the placebo arm. Considering the two-times-per-year administration 
scheme and lower cost than anti-PCSK9 antibodies, inclisiran could be a significantly competitive drug to active and passive immunization approaches.

The cheaper alternatives such as active vaccination inducing ideally permanent endogenous antibodies production could replace the methods of passive immunization with lower costs as well as the lower frequency of injections, and they could find a place in the management of dyslipidemia.

\section{VACCINATION}

In past decades, vaccination was the domain of infectious medicine as the tool to decrease the spread of infectious diseases, and in recent years, also viruses predisposing for cancer. The significant shift in the understanding of vaccines and active immunization happened in recent years. Recent clinical and preclinical studies aimed to target diseases such as Alzheimer's [21], several types of cancer [22], hypertension [23], as well as diabetes mellitus [24], suggested the possibility to modify disease progression. Historically, the first vaccines (first generation) have been composed of fixed or live whole pathogens (measles, mumps, chickenpox, etc.). They contained weakened pathogens that can trigger long-term immunity response; however, in individuals with a weakened immunity, the vaccine can produce the actual disease. The inactivated vaccines, for example, are more stable by the inactivation create the need for additional booster vaccination to obtain the requested immunity. A further second generation of vaccines has used purified proteins obtained from the pathogenic organism (such as hepatitis B vaccine), and later the third generation has consisted of DNA plasmids/naked DNA (influenza, herpes; still in development) which are capable of providing by expression of the crucial protein of the pathogen. The latest generations, however, focus on short amino acid sequences-epitopes [25]. Experimental studies have also shown the possibility of displaying the antigens of HIV or rabies, measles on the attenuated bacteria.
The immune system consists of two big components empirically divided according to the memory aspects and the speed of the reaction: the innate system and the adaptive system. Both of the components interact and work together, although they represent a different approach of the body's defenses against pathogens. The innate system (including component, lysozyme, collectins, interferons, etc.) is a firstline defense, though it is not specific to particular pathogenic agents. They are specific for generally occurring molecular patterns on the pathogens [26]. The important mechanism sensing of antigens and adjuvants by the innate immune system, which later properly activates the adaptive immune response. Under normal conditions, the innate immune system senses foreign antigens through pattern recognition receptors (PRR), for example the well-known Toll-like receptors (TLR), but also C-type lectinlike receptors, receptors sensing viruses as cytosolic RIG-I-like receptors and many others. These receptors sense various substancespathogen-associated molecular patterns (PAMPs) as peptidoglycans, LPS (endotoxin), double-stranded DNA, and single-stranded RNA (viruses and many others) and they are not specific for a certain pathogen. They are located on the membrane of various cells such as dendritic cells (DC) but also other cells of the innate immune system [27]. After successful recognition of PAMPS, the activation of complement, phagocytes as well as cytokine release is triggered. During the infection, granulocytic cells containing neutrophils, eosinophils, and basophils are the first response. The innate immune system can eradicate the pathogen; however, it can also trigger an adaptive immune system consisting of B-cells (antibody-producing cells and antibodies) and T-cells. B-cells (produced in the bone marrow and later residing in lymph nodes, later maturating) can recognize the antigen without the antigen-presenting cells in their native form, and they can later present them to T-helper cells. Mostly those antigens are big polymeric molecules. Those T-independent antigens can activate B-cells directly, though the activation of B-cells without T-helper cells induces weaker immune response and memory. A long-lasting memory and 
proper immune response are the main goals of immunization. By the binging of the antigen to the Fab region of the $\mathrm{B}$ cell receptor together with the cytokines produces by T-helper cells, this region starts the hypermutation and the maturation of $B$ cells into the plasma cells which response by the production and corresponding antibodies to the recognized region of the antigen. By clonal expansion, the cells proliferate and differentiate to plasma cells, eventually to memory cells remaining in the lymph nodes. The adaptive immune response also consists of T-cells (two major types CD4, CD8), which function as cell-mediated immunity. They maturate in the thymus and released to circulation. CD4 cells are essential in the activation of B-cells. Th1 CD4 cells help in cellmediated immune response and Th2 cells trigger antibody-mediated immunity. CD8 cells are important for the cell-mediated immune response. In comparison with B-cells, $\mathrm{T}$ cells require processing and presentation of the antigen by APC to recognize it [28]. The processing of antigens (viral and tumor cells) by APC consists of attaching of antigen with MHC I protein to the surface. Extracellular antigens (bacteria, toxins, pathogens) are attached by MHC II proteins on the surface of APC. By APC activated T-cells later according to the major type CD4 or CD8 trigger B cells activation or contribute on cell-mediated immunity. The first step in the immunization process by vaccines is the recognition of epitopes on the antigens. The epitopes are the small regions on the antigens which are able to stimulate the immune system. The first defense line the imamate immune system will bind or opsonize the agents, and later they will be processed by the APC and presented by MHC proteins on their surface for the activation of the adaptive immune response. APC cells will then activate the different defense response predominantly determined by MHC type [29]. To induce immune response either of regulatory as well as antibody inducing $\mathrm{T}$ cells the vaccines need to contain adjuvants which can be in the past widely used aluminum salts, TLR ligands, nanoparticle formations, squalene oils, or others [30].

However, in comparison with infectious diseases, the origin of the vaccine is the endogenous antigen. From infectious agents, derived vaccines target specific non-self-antigens. In contrast, the non-communicable disease vaccines target the self-protein antigens. For example, in the case of hypertension, the goal is to induce the adaptive immune response against angiotensin-II, or in the case of Alzheimer's disease epitopes of $A \beta$ protein.

\section{PCSK9 ANTIBODY-INDUCING VACCINES}

The fundamental goal of PCSK9 vaccines is to induce a sufficient production of antibodies against PCSK9, which should neutralize the interaction between PCSK9 and LDL-R. Until this time, multiple mostly preclinical studies have proven that PCSK9 vaccines could have these properties. Several preclinical studies have been studying different types of PCSK9 vaccines [31]. Vaccination requires the proper activation of the immune system. However, stimulation of antibody responses directed against the antigen, in our case PCSK9, is limited by the mechanisms of B cell tolerance to the body's own antigens. Though this mechanism is often ineffective and antibody responses are readily elicited by vaccines, particularly those that activate $\mathrm{T}$ helper lymphocytes, which stimulates high activation of antibody production [32, 33]. In the case of the vaccination against self-proteins, several safety tests are required. A vaccine cannot induce the specific $T$ cell response and to have cross-reactivity of antibodies with other endogenous proteins and antigens. During vaccine development, it is important to exclude peptide antigens which have the ability to lead to specific T cell responses. Anti-PCSK9 T-cell response can be accompanied by the lymphocyte infiltration to organs such as liver and destruction of PCSK9-expressing cells. However, to induce the high-affinity antibodies, there is a need for the follicular T helper cells during the $\mathrm{B}$ cells activation, maturation, B cells proliferation, as well as differentiation into plasma cells secreting antibodies as described in the previous section (Crotty, 2011).

The first approach in the development of an anti-PCSK9 vaccine was described by Fattori 
et al. [34]. This study focused on two immunization techniques in mice: DNA and proteinbased vaccination. In the first set of experiments in the mentioned study, DNA plasmid expressing mouse PCSK9 under the human $\mathrm{CMV}$ promoter in conjugation with $\mathrm{CpG}$ oligonucleotide was injected and applied. However, in the first set, no antibody response was observed. In the second step, a xenogeneic approach with a plasmid-expressing human PCSK9 was planned. This approach was successful, and it has resulted in high titers of antihPCSK9 antibodies. In the thirst step, protein immunization was tested and compared with the previous DNA immunization protocol. Highly purified human PCSK9 together with CpG oligonucleotide was applied, resulting in strong anti-hPCSK9 antibody production. In both cases, high anti-hPCSK9 antibody titters resulted in a significant reduction of LDL by up to $40 \%$ after 2 weeks. After 42 days, the cholesterol reduction persisted on $28 \%$ [34].

\section{EPITOPE VACCINES}

An important method in the development of anti-PCSK9 vaccines is the epitope vaccines. They are the novel method in the development, where instead the whole cognate protein only short amino acid sequences of targeted proteins (epitopes) are used. They are characteristic with the more direct and potent immune response than traditional earlier generation vaccines [25]. Epitope strategy requires the exact knowledge of the sequence of amino acids in the immunogenic protein. Reverse vaccinology technique uses the knowledge coding DNA (gene) of the protein of interest, which is further processed and translated to the target protein. This protein is later presented to antigen-presenting cells (APC), which process it. Later, the T cell epitopes are proteolytically harvested and later by the MHC molecules they interact with the receptors of $T$ cells. The epitopes can be identified by the cloning of the domain [35]. The AFFITOPE technology in detailed studied in Alzheimer's vaccines aim to develop the nonself-epitopes, which are very similar to the original but not identical. They aim to overcome humoral and cellular autoimmunity. The limited length of peptides prevents $T$ cell activation, and by this, the cellular autoimmune response and tissue damage [36].

One of the first studies that established the goal to test the peptide-based anti-PCSK9 vaccines was the study of Galabova et al. [37], which tested the AFFITOPE-based anti-PCSK9 active immunization. The goal of the study was to produce an active peptide-based vaccine and to demonstrate the possibilities of reducing total cholesterol as well as LDL levels. They used peptides (8-13 amino acids long) of the N-terminal PCSK9 region, which differed from the amino acids from the native sequence, but they were capable of inducing an immune response. The vaccines themselves consisted of PCSK9 conjugated to the keyhole limpet hemocyanin $(\mathrm{KLH})$ as to the peptide carrier and of the aluminum adjuvant. Protein KLH is the most commonly used carrier for the conjugation of antigens, and it belongs to the group of proteins containing copper in non-heme hemocyanins [38]. After the immunization of Wistar rats in the mentioned study, significant generation of high-affine PCSK9 antibodies was found. Total cholesterol concentrations decreased by the mean value of $30 \%$, and LDL by up to $50 \%$. They have found that PCSK9 humoral immune response and antibody production persisted up to 1 year with the reduction of cholesterol concentrations, without the PCSK9-specific T cell induction, which emphasized that the selected peptides do not compose a $\mathrm{T}$ cell epitope [37]. Study [39] focused on the testing of the above-mentioned anti-PCSK9 vaccine AT04A on a humanized mouse model: $\mathrm{ApoE}^{\star} 3$ Leiden. CETP mice are a double transgenic and are ideal for preclinical tests because they have similar plasma lipid profiles as humans [40]. In preclinical testing of alirocumab on this mice model, a significant decrease of plasma lipids and atherosclerosis was observed [41]. Authors suggested the inhibition of PCSK9 by the vaccine produced antibodies could have the same effect. They have found out that AT04A vaccine induced the effective anti-PCK9 reaction and antibody production following by the significant plasma cholesterol, LDL reduction, 
decreased vascular and overall inflammation and atherosclerosis [39].

\section{OTHER APPROACHES}

Several other teams have also studied the possibilities of anti-PCSK9 vaccines by other approaches and methods $[42,43]$. Crossey et al. designed vaccines that use bacteriophage viruslike particles (QBeta-VLP) which exhibit on the surface PCSK9 peptides together with Freunds and aluminum adjuvant. The mechanism of displaying the self-antigen on the virus-like particle was tested in several studies focusing on vaccines in Alzheimer's disease, hypertension, and cancer [32, 33, 44, 45]. This method has proved that it is capable of inducing a strong antibody response against the self-antigen. In this study, a significant reduction in total cholesterol up to $55 \%$ and other lipid parameters as well was observed. The results of the study corresponded with Alzheimer's disease clinical trial with same QBetal-VLP vaccine, which showed the same antibody response and weak T cell response [46].

Another preclinical study of [47] testing antiPCSK9 on apolipoprotein E deficient mouse used a similar approach as described by Galabova et al. [37]. The vaccine itself consisted of short peptides consisting of 9-10 amino acids (C-terminal sequence of PCSK9 580-589 amino acids) conjugated with KLH as a carrier protein. The length of peptides allowed to prevent the binding to MHC 2 class and the activation PCSK9-specific T cell activation/response. The administration scheme was three times in the 2 -week period. The peak of the antibody titer was reached after 6 weeks. Significant decrease in LDL-C and TC was observed.

A recent study by Montazi-Borojeni et al. [48] investigated the possibility of a nanoliposomebased delivery system. It was based on a similar method as an AFFiRiS group [37]. A peptide different from human or murine was used to be identified as foreign by the immune system and to overcome the self-tolerance. To increase the CD4+ T-cell response, epitope belonging to tetanus toxin was added and coupled with the PCSK9 fragment. The study has revealed that this approach initiated significantly lower response of IFN $\gamma$-producing $\mathrm{CD} 8+$ in comparison with the positive control group, while tetanus peptide can promote CD4+ T-cell response without safety concerns. The values of anti-PCSK9 antibodies were the highest in the eighth week and persisted up to the 48th week, however with almost five times lower values.

Nowadays, phase I. clinical study assessing safety, immunogenicity and LDLc -lowering activity of 2 PCSK9 targeting AFFITOPE vaccines in healthy subjects (AFF012), ClinicalTrials.gov Identifier: NCT02508896 is ongoing. However, the updates and the results had yet to be provided by the day of writing this article according to the marked schedule [49].

\section{CONCLUSIONS}

Currently, methods of active immunization directed against PCSK9 represent an interesting alternative to passive immunization by administering antibodies. Active immunization would have an interesting application in the presumed better adherence, significantly lower cost of treatment. However, there are currently no significant clinical studies investigating the possibility of active immunization against PCSK9 that could provide us with clinically suitable treatment in the near future. The possibilities of PCSK9 vaccinations look promising, however the monoclonal antibodies to PCSK9 were approved in Europe and in the US only in 2015 and there are needed a real-life data, how the long-term permanent PCSK9 inhibition is affecting other biological processes in the body and the safety of the therapy.

\section{ACKNOWLEDGEMENTS}

Funding. This study was carried out with the grant support: VEGA No1/0780/19 and APVV no. 17-0550. No Rapid Service Fee was received by the journal for the publication of this article.

Authorship. All named authors meet the International Committee of Medical Journal 
Editors (ICMJE) criteria for authorship for this article, take responsibility for the integrity of the work as a whole, and have given their approval for this version to be published.

Disclosures. Jan Fedacko, Stefan Toth, and Dominik Pella have nothing to disclose.

Compliance with Ethics Guidelines. This article is based on previously conducted studies and does not contain any studies with human participants or animals performed by any of the authors.

Data Availability. Data sharing is not applicable to this article as no datasets were generated or analyzed during the current study.

Open Access. This article is licensed under a Creative Commons Attribution-NonCommercial 4.0 International License, which permits any non-commercial use, sharing, adaptation, distribution and reproduction in any medium or format, as long as you give appropriate credit to the original author(s) and the source, provide a link to the Creative Commons licence, and indicate if changes were made. The images or other third party material in this article are included in the article's Creative Commons licence, unless indicated otherwise in a credit line to the material. If material is not included in the article's Creative Commons licence and your intended use is not permitted by statutory regulation or exceeds the permitted use, you will need to obtain permission directly from the copyright holder. To view a copy of this licence, visit http://creativecommons.org/licenses/by$\mathrm{nc} / 4.0 /$.

\section{REFERENCES}

1. Ference BA, Ginsberg HN, Graham I, et al. Lowdensity lipoproteins cause atherosclerotic cardiovascular disease. 1. Evidence from genetic, epidemiologic, and clinical studies. A consensus statement from the European Atherosclerosis Society Consensus Panel. Eur Heart J. 2017;38:2459-72. https://doi.org/10.1093/eurheartj/ehx144.
2. Shapiro-Shelef M, Calame K. Regulation of plasmacell development. Nat Rev Immunol. 2005;5: 230-42.

3. Catapano AL, Graham I, Backer De, Cooney G, et al. ESC/EAS guidelines for the management of dyslipidaemias: the task force for the management of dyslipidaemias of the European Society of Cardiology (ESC) and European Atherosclerosis Society (EAS) Developed with the special contribution of the European Association for Cardiovascular Prevention \& Rehabilitation (EACPR). Atherosclerosis. 2016;2016(253):281-344.

4. Mendis S, Chestnov O. The global burden of cardiovascular diseases: a challenge to improve. Curr Cardiol Rep. 2014;16:486.

5. Baigent C, Blackwell L, Emberson J, Holland LE, Reith C, Bhala N, Peto R, Barnes EH, Keech A, Simes J, Collins R, Cholesterol Treatment Trialists' (CTT) Collaboration. Efficacy and safety of more intensive lowering of LDL cholesterol: a meta-analysis of data from 170,000 participants in 26 randomised trials. Lancet. 2010;376:1670-81. https://doi.org/10.1016/ s0140-6736(10)61350-5.

6. Pittman DG, Chen W, Bowlin SJ, Foody JM. Adherence to statins, subsequent healthcare costs, and cardiovascular hospitalisations. Am J Cardiol. 2011;107(11):1662-6.

7. Zhang L, Song K, Zhu M, Shi J, Zhang H, Xu L, Chen Y. Proprotein convertase subtilisin/kexin type 9 (PCSK9) in lipid metabolism, atherosclerosis and ischemic stroke. Int J Neurosci. 2016;126(6): 675-80. https://doi.org/10.3109/00207454.2015. 1057636 .

8. Weinreich M, Frishman WH. Antihyperlipidemic therapies targeting PCSK9. Cardiol Rev. 2014;22(3): 140-6.

9. Davis CG, Goldstein JL, Südhof TC, et al. Acid-dependent ligand dissociation and recycling of LDL receptor mediated by growth factor homology region. Nature. 1986;326:760-5.

10. Rudenko G, Henry L, Henderson K, et al. Structure of the LDL receptor extracellular domain at endosomal pH. Science. 2002;298:2353-8.

11. Chernogubova E, Strawbridge $R$, Mahdessian $H$, Mälarstig A, Krapivner S, Gigante B, Hellénius ML, de Faire U, Franco-Cereceda A, Syvänen AC, Troutt JS. Common and low-frequency genetic variants in the PCSK9 locus influence circulating PCSK9 levels. Arterioscleros Thromb Vasc Biol. 2012;32(6): 1526-34.

12. Koren MJ, Lundqvist $P$, Bolognese $M$, Neutel JM, Monsalvo ML, Yang J, Kim JB, Scott R, Wasserman 
SM, Bays H, MENDEL-2 Investigators. Anti-PCSK9 monotherapy for hypercholesterolemia: the MENDEL-2 randomised, controlled phase III clinical trial of evolocumab. J Am Coll Cardiol. 2014;63(23): 2531-40.

13. Lyall D, Ward J, Banach M, Smith GD, Gill J, Pell J, Holmes M, Sattar N (2018) PCSK9 genetic variants, life-long lowering of LDL-cholesterol and cognition: a large-scale Mendelian randomisation study. bioRxiv. 2018;335877. https://www.biorxiv.org/ content/10.1101/335877v1. Accessed 12 Mar 2020.

14. Cohen JC, Boerwinkle E, Mosley TH Jr, Hobbs HH. Sequence variations in PCSK9, low LDL, and protection against coronary heart disease. $\mathrm{N}$ Engl J Med. 2006;354:1264-72.

15. Rosenson RS, Hegele RA, Koenig W. Cholesterollowering agents: PCSK9 inhibitors today and tomorrow. Circ Res. 2019;124(3):364-85.

16. Sabatine MS, Giugliano RP, Keech AC, Honarpour N, Wiviott SD, Murphy SA, Kuder JF, Wang H, Liu T, Wasserman SM, Sever PS, Pedersen TR, FOURIER Steering Committee and Investigators. Evolocumab and clinical outcomes in patients with cardiovascular disease. N Engl J Med. 2017;376:1713-22. https://doi.org/10.1056/nejmoa1615664.

17. Schwartz GG, Bessac L, Berdan LG, et al. effect of alirocumab, a monoclonal antibody to PCSK9, on long-term cardiovascular out- comes following acute coronary syndromes: rationale and design of the ODYSSEY outcomes trial. Am Heart J. 2014;168: 682-9. https://doi.org/10.1016/j.ahj.2014.07.028.

18. Schwartz GG, Steg PG, Szarek M, ODYSSEY OUTCOMES Committees and Investigators, et al. Alirocumab and cardiovascular outcomes after acute coronary syndrome. N Engl J Med. 2018;379: 2097-107. https://doi.org/10.1056/nejmoa1801174.

19. García RC, Cid CM, Ruiz AS, López AM, Cano EP, López YJ, Rojas JJ. 4CPS-020 use, efficacy and adherence to treatment with PCKS9 inhibitors in real clinical practice. Eur J Hosp Pharm. 2020;27: A56.

20. Ray KK, Wright RS, Kallend D, Koenig W, Leiter LA, Raal FJ, Bisch JA, Richardson T, Jaros M, Wijngaard PL, Kastelein JJ. Two phase 3 trials of inclisiran in patients with elevated LDL cholesterol. N Engl J Med. 2020;382:1507-19.

21. Lambracht-Washington D, Rosenberg RN. Advances in the development of vaccines for Alzheimer's disease. Discov Med. 2013;15:319-26.

22. Melero I, Gaudernack G, Gerritsen W, Huber C, Parmiani G, Scholl S, Thatcher N, et al. Therapeutic vaccines for cancer: and overview of clinical trials. Nat Rev Clin Oncol. 2014;11:509-24.

23. Ambuhl PM, Tissot AC, Fulurja A, Maurer P, Nussberger J, Sabat R, Nief $V$, et al. A vaccine for hypertension based on virus like particles: preclinical efficacy and phase I safety and immunogenicity. J Hypertens. 2007;25:63-72.

24. Wherrett DK, Bundy B, Becker DJ, DiMeglio LA, Gitelman SE, Goland R, Gottlieb PA, et al. Antigenbased therapy with glutaminic acid decarboxylase (GAD) vaccine in patients with recent-onset type 1 diabetes: a randomised double-blind trial. Lancet. 2011;378:319-27.

25. Kao DJ, Hodges RS. Advantages of a synthetic peptide immunogen over a protein immunogen in the development of an anti-pilus vaccine for Pseudomonas aeruginosa. Chem Biol Drug Des. 2009;74:33-42. https://doi.org/10.1111/j.17470285.2009.00825.x.

26. Goldsby R, Kindt TJ, Osborne BA, Kuby J. Chapter 2: Cells and Organs of the Immune System. In: Immunology, 5th ed. New York: W.H. Freeman and Company; 2003. pp 24-56.

27. Kawai T, Akira S. The role of pattern-recognition receptors in innate immunity: update on Toll-like receptors. Nat Immunol. 2010;11:373-84.

28. Margolick JB, Markham RB, Scott AL. Infectious disease epidemiology: theory and practice. Chapter 10. In: Nelson KE, Masters CF, editors. The immune system and host defense against infections. Boston: Jones and Bartlett; 2006. p. 317-43.

29. Schijns VE (2001) Activation and programming of adaptive immune responses by vaccine adjuvants. [Last cited on 2010 Jan 7]. http://www.vetscite.org/ publish/articles/000027/index.html. Accessed 12 Mar 2020.

30. McKee AS, Marrack P. Old and new adjuvants. Curr Opin Immunol. 2017;47:44-51.

31. Kobiyama K, Saigusa R, Ley K. Vaccination against atherosclerosis. Curr Opin Immunol. 2019;59: $15-24$.

32. Chackerian B, Durfee MR, Schiller JT. Virus-like display of a neo-self-antigen reverses B cell anergy in a B cell receptor transgenic mouse model. J Immunol. 2008;180:5816-25.

33. Chackerian B, Durfee MR, Schiller JT. Virus-like display of a neo-self-antigen reverses B cell anergy in a B cell receptor transgenic mouse model. J Immunol. 2008;180:5816-25. 
34. Fattori E, Cappelletti M, Lo Surdo P, Calzetta A, Bendtsen C, Ni YG, Pandit S, Sitlani A, Mesiti G, Carfi A, Monaci P. Immunization against proprotein convertase subtilisin-like/kexin type 9 lowers plasma LDL-cholesterol levels in mice. J Lipid Res. 2012;53:1654-61.

35. Jurtz V, Paul S, Andreatta M, Marcatili P, Peters B, Nielsen M. NetMHCpan-4.0: improved peptideMHC class I interaction predictions integrating eluted ligand and peptide binding affinity data. J Immunol. 2017;199:3360-8. https://doi.org/10. 4049/jimmunol.1700893.

36. Schneeberger A, Mandler M, Otava O, Zauner W, Mattner F, Schmidt W. Development of AFFITOPE vaccines for Alzheimer's disease (AD)-from concept to clinical testing. JNHA. 2009;13(3):264-7.

37. Galabova G, Brunner S, Winsauer G, et al. Peptidebased anti-PCSK9 vaccines-an approach for longterm LDLc management. PLoS ONE. 2014;9: e114469.

38. Harris JR, Markl J. Keyhole limpet hemocyanin (KLH): a biomedical review. Micron. 1999;30(6): 597-623.

39. Landlinger C, Pouwer MG, Juno C, van der Hoorn JW, Pieterman EJ, Jukema JW, Staffler G, Princen HM, Galabova G. The AT04A vaccine against proprotein convertase subtilisin/kexin type 9 reduces total cholesterol, vascular inflammation, and atherosclerosis in APOE* $^{*}$ 3Leiden, CETP mice. Eur Heart J. 2017;38(32):2499-507.

40. Westerterp M, van der Hoogt CC, de Haan W, Offerman EH, Dallinga-Thie GM, Jukema JW, Havekes LM, Rensen PC. Cholesteryl ester transfer protein decreases high-density lipoprotein and severely aggravates atherosclerosis in APOE* 3-Leiden mice. Arterioscler Thromb Vasc Biol. 2006;26(11):2552-9.

41. Kuhnast S, van der Hoorn JW, Pieterman EJ, van den Hoek AM, Sasiela WJ, Gusarova V, Peyman A, Schafer HL, Schwahn U, Jukema JW, Princen HM.
Alirocumab inhibits atherosclerosis, improves the plaque morphology, and enhances the effects of a statin. J Lipid Res. 2014;55:2103-12.

42. Chackerian B, Remaley A. Vaccine strategies for lowering LDL by immunisation against proprotein convertase subtilisin/kexin type 9. Curr Opin Lipidol. 2016;27:345-50.

43. Crossey E, Amar MJ, Sampson M, Peabody J, Schiller JT, Chackerian B, Remaley AT. A cholesterol-lowering VLP vaccine that targets PCSK9. Vaccine. 2015;33:5747-55.

44. Bachmann MF, Whitehead P. Active immuno therapy for chronic diseases. Vaccine. 2013;31: 1777-84.

45. Tissot AC, Maurer P, Nussberger J, Sabat R, Pfister T, Ignatenko $S$, et al. Effect of immunisation against angiotensin II with CYT006-AngQb on ambulatory blood pressure: a double-blind, randomised, placebo-controlled phase IIa study. Lancet. 2008;371: 821-7.

46. Chackerian B, Rangel M, Hunter Z, Peabody DS. Virus and virus-like particle-based immunogens for Alzheimer's disease induce antibody responses against amyloid- $\beta$ without concomitant $\mathrm{T}$ cell responses. Vaccine. 2006;24(37-39):6321-31.

47. Kawakami R, Nozato Y, Nakagami H, Ikeda Y, Shimamura M, Yoshida S, Sun J, Kawano T, Takami Y, Noma T, Rakugi H. Development of vaccine for dyslipidemia targeted to a proprotein convertase subtilisin/kexin type 9 (PCSK9) epitope in mice. PLoS ONE. 2018;13(2):e0191895.

48. Momtazi-Borojeni AA, Jaafari MR, Badiee A, Sahebkar A. Long-term generation of antiPCSK9 antibody using a nanoliposome-based vaccine delivery system. Atherosclerosis. 2019;1(283):69-78.

49. https://clinicaltrials.gov/ct2/show/NCT02508896. Accessed 12 Mar 2020. 